\title{
Development of a professional practice competency for undergraduate nursing students: A mixed-method study
}

\author{
Chris Adams*1, Kylie Russell ${ }^{1,2}$, Tracey Coventry ${ }^{1,2}$ \\ ${ }^{1}$ School of Nursing \& Midwifery, University of Notre Dame Australia, Fremantle, Australia \\ ${ }^{2}$ School of Medicine, University of Notre Dame Australia, Fremantle, Australia
}

Received: March 30, 2021

DOI: $10.5430 /$ jnep.v11n10p33
Accepted: June 10, 2021

Online Published: June 16, 2021

URL: https://doi.org/10.5430/jnep.v11n10p33

\begin{abstract}
Nursing professionalism relates to the knowledge, skills, conduct, behaviour and attitudes of registered nurses. Difficulties related to student assessment of professionalism have been anecdotally described as a disparity between the meaning of the term 'professionalism' to nurses and its application and measurement in clinical practice. The aim of this study was to develop a professional practice competency for undergraduate nurses on clinical placement. An exploratory sequential mixed-methods approach with a two-phase design was used to develop the competency. Phase one, the Delphi method with 16 expert nurses, was used to develop the competency. This involved the thematic analysis of key statements over four rounds, five key themes were identified (attitudes, communication, knowledge, standards, relationships) that formed the framework and 33 individual competency statements. This was followed by phase 2, content validity, using the Table of Specification with 58 clinical facilitators. The findings confirmed the statements ( $80 \%$ consensus) deemed important to assess the essential construct of nursing professional practice. It is envisaged that the professional practice competency will assist student insight into their professional role and subsequently allow adjustment and achievement of professional practice competency.
\end{abstract}

Key Words: Professional practice, Nursing education, Undergraduate education, Student nurse, Competency assessment

\section{INTRODUCTION}

The importance of professionalism has been described as a dynamic entity in healthcare, ${ }^{[1]}$ where the expectations of society are changing as both societies and cultures change. ${ }^{[2]}$ Despite this, Duphily ${ }^{[3]}$ asserts there are constant elements of professionalism; attitudes, skills, behaviours, attributes and values expected of those considered experts in a particular field by a particular society at a particular time and place. Professionalism has long been viewed as a structurally stabilising and morally protective force in society. ${ }^{[4]}$ More recently, professionalism has been described as a conduit through which a profession becomes worthy of the respect and trust of the public. ${ }^{[5]}$ In addition, professionalism plays a role in building trust and therapeutic relationships between patients and health professionals, such as nurses. ${ }^{[2]}$ The advancement of technology and medical knowledge, higher levels of professional accountability and responsibility, demands of cost containment and health priority of quality improvement all contribute to the evolution of and change to the understandings of professionalism. ${ }^{[6]}$

\footnotetext{
*Correspondence: Chris Adams; Email: chris.adams@nd.edu.au ; Address: 19 Mouat Street, School of Nursing \& Midwifery, University of Notre Dame Australia, Fremantle 6959, Western Australia.
} 
Difficulties related to the assessment of professionalism have been described as a disparity between the meaning of the term 'professionalism' to nurses and its application and measurement in clinical practice. The clinical assessment tool used at the research site, referred to as the NCAS (Nursing Competency Assessment Schedule) ${ }^{[7]}$ is suitable to measure the clinical performance of undergraduate students on practicum, yet does not adequately provide assessment and opportunity for feedback on professional knowledge, skills and attitudes. As a result of the lack of a specific measure of professionalism, nursing staff may encounter difficulties in assessing and managing unprofessional conduct among undergraduate nursing students in the current time-poor work setting. The consequence for the student is a delay in receiving timely and constructive feedback in the context of the practicum setting, thereby negating the opportunity for the student to demonstrate improvement prior to failing or being required to repeat the practicum placement. Students frequently express disappointment at the absence of contem- poraneous feedback about perceived unprofessional conduct by supervising staff. This subsequent lost learning moment for the undergraduate nurse precludes the opportunity to respond and demonstrate improvement based on the feedback, and disrupts the aims of experiential learning during practicum and the student's ability to achieve course learning outcomes.

This study developed the professional practice competency to assess the professional knowledge, skills, attitudes and conduct of undergraduate nursing students at formative and summative points during a practicum placement. In addition, consideration of the University objects, which articulate the provision of education in the context of Catholic faith and values were included. The objects are further expressed through the 10 graduate attributes which aim to foster and grow the qualities of ethical practice, interpersonal skills, professionalism, specialist knowledge, and skills to support local and global communities. These attributes are summarised in Table 1.

Table 1. The university graduate attributes

\begin{tabular}{|l|l|}
\hline Communication & Communicate effectively within a range of contexts \\
\hline Critical and Reflective Thinking & $\begin{array}{l}\text { Practice reflectively with sound decision-making abilities, critical thinking and effective problem } \\
\text { solving }\end{array}$ \\
\hline $\begin{array}{l}\text { Technical Competence and } \\
\text { Interdisciplinarity }\end{array}$ & Comprehensive technical and interprofessional knowledge extending beyond a single discipline \\
\hline Lifelong Learning & Personally accountable for lifelong learning and professional development \\
\hline Ethical Responsibility & $\begin{array}{l}\text { A capacity to apply high ethical standards, both personally and professionally, to societal } \\
\text { problems and challenges }\end{array}$ \\
\hline $\begin{array}{l}\text { Philosophical and Religious } \\
\text { Approaches to Life }\end{array}$ & $\begin{array}{l}\text { The ability to be an open and reflective individual, sensitive to and accepting of others' values } \\
\text { and beliefs }\end{array}$ \\
\hline Teamwork & A capacity to contribute in a positive and collaborative manner to achieve common goals \\
\hline $\begin{array}{l}\text { Research and Information } \\
\text { Retrieval Skills }\end{array}$ & $\begin{array}{l}\text { The ability to construct new concepts or create new understandings through the process of } \\
\text { research and inquiry }\end{array}$ \\
\hline Internationalisation & Appreciation of social and cultural diversity and individual human rights in a global context \\
\hline $\begin{array}{l}\text { Commitment to Active } \\
\text { Citizenship }\end{array}$ & A commitment to connect with and serve the community \\
\hline
\end{tabular}

The purpose of the competency is to assist in developing undergraduate practice that aligns with the professional expectations of safe, kind and compassionate nursing practice. ${ }^{[8]}$ Academic staff are expected to assist students to achieve the graduate attributes by exhibiting authentic Catholicity and pursuing excellence in academic endeavours, with particular emphasis on teaching, scholarship and research. ${ }^{[9]}$

\section{MethodS}

The researcher's aim was to develop a professional practice competency in line with the strategic plan ${ }^{[9]}$ and graduate attributes $^{[10]}$ of a Western Australian (WA) private catholic university (hereafter referred to as the University). The purpose of a professional practice competency is to assess the professional knowledge, skills, attitudes and conduct of undergraduate nursing students during practicum placement. This competency will assist in developing undergraduate practice that aligns with the professional expectations of safe, kind and compassionate nursing practice ${ }^{[8]}$ and the Objects and graduate attributes of the university. The purpose of this paper is to describe the development and validity testing of the competency that was undertaken as part of a research 
degree.

\subsection{Site}

The research site is an accredited Bachelor of Nursing (BN) course provider that currently offers extensive clinical practicum hours in Australia, comprising 1,120 hours across the three-year degree. The NCAS provides the main source of assessment for the professional practice courses throughout the six semesters of the degree. Academic responsibility to evaluate student course learning outcomes and the assessment material used to measure these outcomes is a critical component of the role of lecturer, and affirms the need to develop a competency to assess graduate attributes at the research site. ${ }^{[11]}$ Additionally, as a university providing education in the context of Catholic faith and values, it is an academic responsibility to provide opportunity to achieve the graduate attributes during work integrated learning and thereby, demonstrate that professionalism, the university objects and the graduate attributes conjoin as mutually achievable outcomes for nursing students from both an academic and nursing perspective. In processes such as course reviews and course accreditations, it is a requirement that tertiary institutions are able to articulate the ways student learning outcomes are evaluated or assessed. ${ }^{[11]}$ The development of a professional practice competency will assist undergraduate nursing students to gain valuable and timely insight into their own professional role and the university and clinical expectations, and subsequently allow adjustment and achievement of the competency in a real-time context.

\subsection{Method}

This research used an exploratory sequential mixed-methods design to develop and validate the Competency to assess undergraduate nursing professional practice during clinical practicum. A sequential design dicates the collection and analysis of qualitative data prior to quantitative data. The research design consisted of a two-phase approach, a Delphi panel and Table of Specifications (ToS).$^{[12]}$

The Delphi method was used for the qualitative phase of this study (Phase 1). This commonly used formal consensus development method offered a structured, transparent and replicable way of synthesising and collating individual expert opinion. ${ }^{[12,13]}$ Foth et al. ${ }^{[14]}$ reported that Delphi is a popular method of data collection used to develop competencies, curriculum and assessment tools in nursing, and is widely used in health research. ${ }^{[15]}$

Phase 1 was followed by content validity of the competency using the established method of ToS. ${ }^{[16]}$ The ToS is described as a blueprint for competency development, which in this study, involved comparison of expected behaviours and the

Published by Sciedu Press ability of the Competency to assess this. ${ }^{[16]}$ The TOS method required clinical facilitators-who supervise students on clinical placement - to rate each statement on a five-point Likert scale in reference to its ability to measure professionalism in practice. The purpose of estimating the validity of the professional practice competency was to ensure it could measure what it was designed to measure, and thereby add rigour to the study and ensure practical application of the assessment criteria in assessing undergraduate nursing professional practice.

Prior to any research being undertaken, the researcher gained the University Human Research Ethics Committee approval (017209F). The research was completed for the requirements of a Masters of Nursing (Research) with two research supervisors.

\section{RESUlts}

The Phase 1 Delphi panel provided face validity of the Competency assessment criteria over four iterative and generative rounds of data collection. 35 senior nurses were invited to participate as Delphi panellists with a final participant number of 16 expert nurses remaining throughout all four rounds. The expert Delphi panel comprised of nurses who - had a minimum of 10 years of clinical practice, and a role in either the management of nursing staff, coordination of undergraduate and/or graduate clinical nursing programs, nursing academic with expertise in professional practice education and assessment, or published work in the area. A mix of metropolitan $(n=11)$ and rural $(n=5)$ nurses were represented in the Delphi panel. The Delphi panellists had a collective nursing experience of 297 years (mean $=24.75$ years). The panel consisted of one male and 15 females.

The data presented opinions and views on undergraduate nursing professionalism using thematic analysis ${ }^{[17]}$ to interpret data sequentially, thereby informing the development of the criteria. On completion of each round of data collection, data was coded into categories and then organised into themes. ${ }^{[15]}$ Draft statements were then provided back to the Delphi panel for further comment and member checking undertaken to ensure researcher interpretation of data was accurate. Three rounds of data collection and analysis were completed with 125 statements initially developed following Round 1, being refined to 31 statements in Round 3. Round 4 involved revisiting excluded criteria, and the Delphi panellists were asked to undertake a final review and ranking of the 31 preferred statements, and to review the 18 excluded statements and rank these if they believed the statements warranted inclusion in the competency. As a result, 33 statements were developed under the headings of knowledge, skills and attitudes. A consensus of over $73 \%$ 
was achieved, with the key professional themes identified by the participants articulated in Figure 1. This concluded the Delphi Panel rounds and the final draft professional practice competency was then placed into a Table of Specifications format in readiness for phase two data collection.

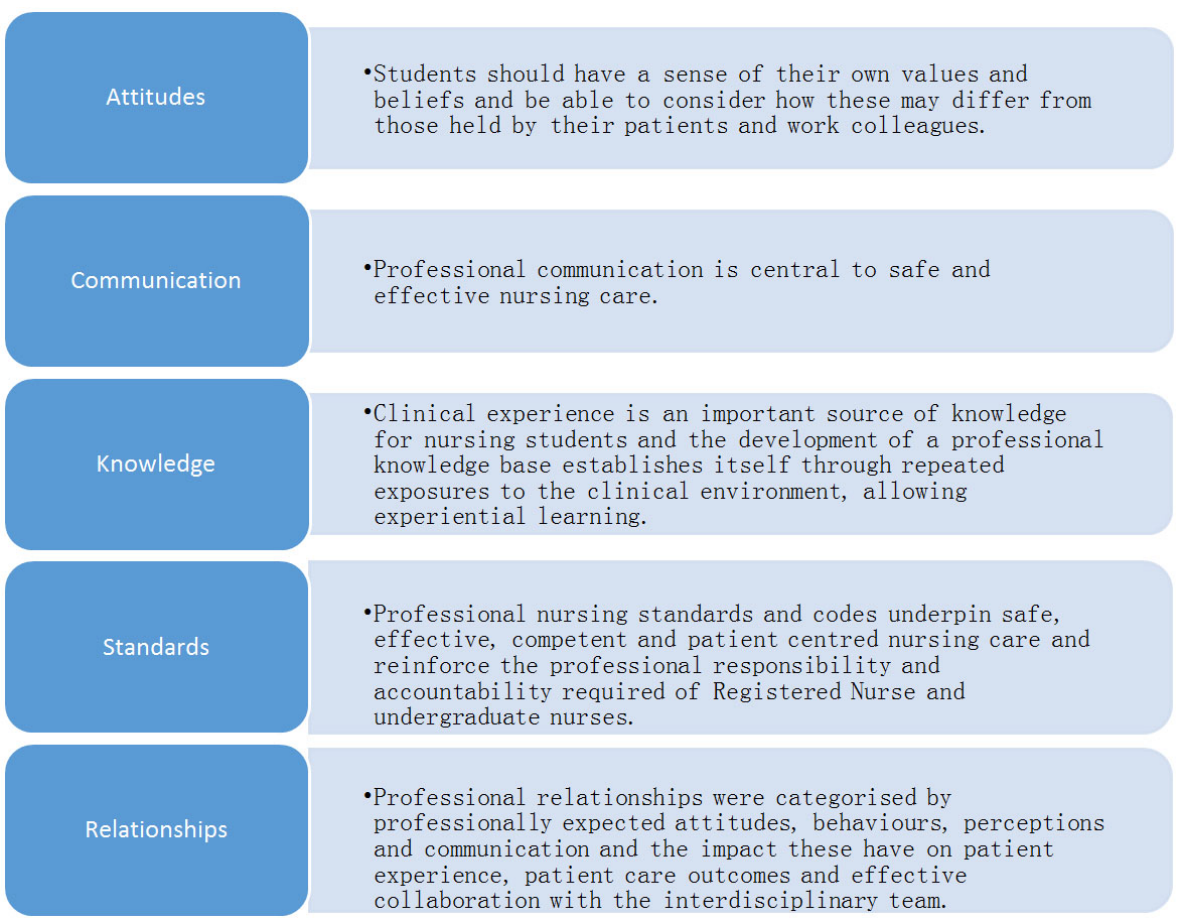

Figure 1. Summary of Phase 1-Delphi findings

Phase two provided content validity of the proposed competency through use of a Table of Specifications (ToS) Methodology. ${ }^{[16,18-20]}$ A ToS, sometimes called a test blueprint, is a table that aligns course objectives, instruction and assessment ${ }^{[21]}$ and is used to provide accountability of teacher made tests, in the education setting. ${ }^{[20]}$ ToS is characterized by comparison of observed and expected assessment criteria $^{[18,19]}$ and the ability of these assessment criteria to consistently measure or test to the degree they were designed to measure. ${ }^{[19,21]}$ The 58 end-users of the Competency (the CFs) endorsed all 33 statements. The ToS validation of the 33 Competency statements produced descriptive statistics following data input into the TOS (see Figure 2).

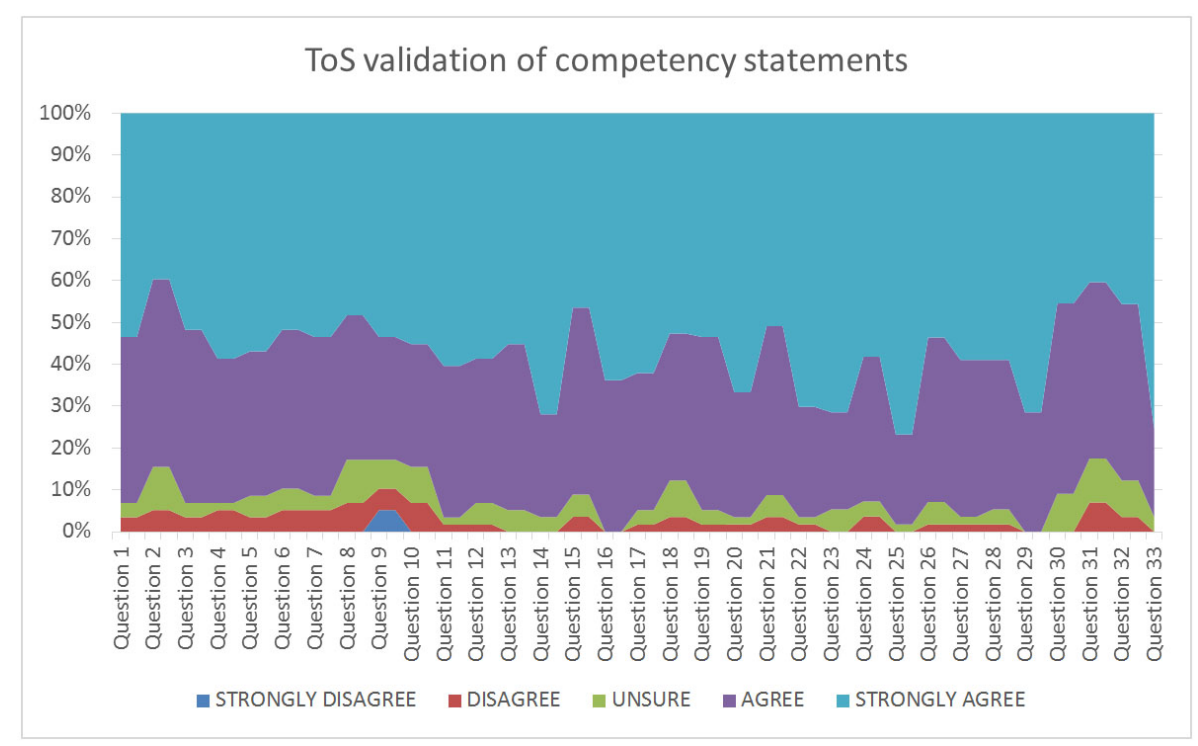

Figure 2. ToS Validation 
The findings of Phases 1 and 2 confirmed the statements ing-professional practice. These Competency statements deemed important to assess the essential construct in nurs- are detailed in Table 2.

Table 2. Professional practice competency statements

\section{Professional Practice Competency Statements (33)}

1) Integrates NMBA Code of Conduct for Nurses and Registered Nurse Standards for Practice, ICN Code of Ethics for Nurses, Health Practitioner Regulation National Law (WA) Act 2010, Mental Health Act (2014), Medicines and Poisons Act 2014 and mandatory reporting obligations of the RN into practice as a student RN.

2) Prioritises accountability in decision making and integrates knowledge of open disclosure process in practice.

3) Prioritises decision making and adapts practice to comply with codes, standards and legislation governing nursing practice within current scope.

4) Demonstrates systematic patient assessment, analysis of findings and ability to prioritise and coordinate patient care.

5) Integrates recognised reporting mechanisms to escalate patient care in response to clinical deterioration.

6) Demonstrates accountability in decision making and practice.

7) Analyses assessment results and collaborates in decision making and care planning with mentoring staff.

8) Integrates sound knowledge of pathophysiology and pharmacology to support clinical decision making.

9) Applies National Safety and Quality Health Service Standards to patient care.

10) Incorporates NMBA code of conduct and ICN code of ethics in communication, behaviour and attitudes in and out of the clinical setting.

11) Demonstrates understanding of responsibility for duty of care to patients and their families.

12) Demonstrates timely and responsive care to ensure patient safety in a changing environment.

13) Applies evidence-based theory to practice.

14) Ensures safety of self and others during nursing interventions.

15) Demonstrates flexibility and an ability to multi-task workload.

16) Independently establishes and works within own scope of practice.

17) Demonstrates sound interpersonal skills in effective interprofessional communication.

18) Advocates for patients.

19) Applies critical thinking and analysis to enable problem solving.

20) Demonstrates ability to work as an effective team member.

21) Independently identifies and manages patient activities of daily living.

22) Presents to placement adequately prepared, with an inquiring mind and positive attitude, and is receptive to feedback.

23) Demonstrates sensitivity and acceptance of others' beliefs, values and differences in provision of person-centred care.

24) Reflects on past experiences and applies this knowledge to enable adaptation to clinical environment.

25) Acts in a professional and respectful manner at all times.

26) Rationalises decision making with reflective and evidence-based responses.

27) Identifies, respects and maintains professional boundaries with patients and their family, visitors and staff.

28) Relates and values staff contribution to learning on practicum.

29) Consistently provides patient-centred care.

30) Develops a plan to manage identified learning needs.

31) Identifies and appropriately manages own response to stress.

32) Demonstrates emotional intelligence in practice and interactions with others.

33) Represents the University and self in a professional manner through both appearance and engagement with placement.

Development of the Competency over two phases allowed consideration of professional codes and standards and contemporary literature alongside the unique requirements and graduate attributes of the University. The Competency, as outlined in Table 2, was developed to reflect the same method of assessment in the NCAS, being contextual and contemporaneous in each placement the student undertakes. The competency is assessed using the Bondy criterion in the 
NCAS. ${ }^{[22]}$ The Bondy criterion provide the assessor with a psychometrically effective and efficient rating scale to assess student clinical performance, utilising five competency levels ranging from independent or safe and knowledgeable, to marginal and dependent, referring to concerns about unsafe practice. The new Competency is in addition to the existing eight NCAS employer competencies, with a final total of nine competency assessments. These are Professional Practice competency, Caring for a client/patient requiring wound management, Managing medication administration, Managing the care of a client/patient, Managing the care of a group of clients/patients, Monitoring and responding to changes in a client's/patient's condition, Teaching a client/patient, Teaching of a colleague and The initial and ongoing nursing assessment of a client/patient.

\section{Discussion}

As a profession, nursing embodies and promotes core values such as human dignity, integrity, autonomy, altruism and social justice. ${ }^{[23]}$ A professional nurse incorporates and articulates these values while demonstrating professional and ethical practice. These values are further supported by Miracle, ${ }^{[24]}$ who described professional values as caring, human dignity, social justice, honesty, compassion, curiosity, empathy, social responsibility and accountability. The $\mathrm{NMBA}^{[8]}$ Code of Conduct for Nurses espouses the values of integrity, honesty, respect and compassion, which should be represented by nurses in the undertaking of their duties. The professional practice competency aims to enhance the assessment of undergraduate nursing practice at the research site, as it incorporates these values of the nursing profession, while also providing a means to assess achievement of the graduate attributes.

The Behavioural Inventory for Professionalism in Nursing (BIPN) was developed in the United States by Miller, Adams, and Beck. ${ }^{[25]}$ This evaluative behavioural inventory was based on Miller's Model, (1988) termed the 'Wheel of Professionalism in Nursing', which has been translated and used in over 30 countries to assess professionalism in nursing against nine categories. ${ }^{[26]}$ Miller et al. ${ }^{[25]}$ identified and combined professional behaviours in nursing from those previously depicted by sociologists, nurse leaders, the American Nurses Association (ANA) policy statement, standards of practice and the ANA Code of Ethics for Nurses. ${ }^{[25,26]}$ Miller's Model provided the researcher with a framework of language and assessment strategies which were incorporated into the first Delphi round questions.

Levett-Jones et al. ${ }^{[27]}$ recently developed the Patient Safety Competency Framework for Nursing Students, identifying nine areas deemed critical on entry to nursing practice. These nine critical areas of competence in safe nursing practice are 'person-centred care; therapeutic communication; cultural competence; teamwork and collaborative practice; clinical reasoning; evidence-based practice; preventing, minimising and responding to adverse events; infection prevention and control; and medication safety'. [27] Emergent themes from the study were similar in content to professionalism in practice, and provide substantiation that the data from the study were consistent with similar research findings. ${ }^{\text {[27] }}$ In particular, the themes included the areas of person-centred care, therapeutic communication, cultural competence, teamwork and collaborative practice, clinical reasoning and evidencebased practice. Those aspects not included in the professional practice competency sat outside the professionalism framework and were otherwise assessed in the clinical competency statements included in the NCAS.

\subsection{Implications}

It is envisaged that adoption of the Competency will provide students and CFs with a framework for learning and assessing the concept of nursing professionalism. Students require ongoing support in work integrated learning practicums across the $\mathrm{BN}$ degree and through these explicit statements, may be guided toward the expected requirements and assessment measures. To further understand this impact, the Competency is being trialled in the third-year nursing student NCAS. Student and CF feedback will be sought as to its usefulness and timeliness of student assessment related to nursing professionalism to support early interventions. This will include the impact on time for completion of the competency, and potential saved time due to early identification. It is acknowledged that the management of unprofessional conduct in undergraduate nursing practice is time consuming and difficult because of the lack of clear measures of competence. It is anticipated that this early intervention will prevent implications related to student nursing professionalism as well as the link to demonstrating achievement of the graduate attributes of the University.

\subsection{Limitations}

This research was limited to the research site undergraduate program and subsequently does not represent the nursing student population. The transferability of findings to other nursing programs may be somewhat limited because of the content validity testing of the developed Competency, as undertaken for the University graduate attributes, however it must be noted that whilst these graduate attributes are unique in their wording, they are not unique in their intent, and thus have wide applicability. The scope of the study did not allow for testing of the Competency in practice. Therefore, its usability for determining professionalism of the undergraduate 
nursing student remains unknown, this phase of the study is currently in process.

\section{Conclusion}

The professional practice competency aims to address the identified assessment gap in the NCAS and provide a framework for learning and assessing the concept of nursing professionalism in the context of the standards and codes expected of the nursing profession as well as university graduate attributes. This research has identified the constructs of professional practice, within the context of a small study site, and reassuringly affirmed that these values still exist and are highly regarded and valued by nursing experts in this technically advanced and contemporary era of nursing. Delphi responses yielded interesting and variable views and opinions, allowing development of the professional practice competency through careful consideration of national and international standards and of the graduate attributes. The importance of professional nursing practice, as voiced by these expert nurses, affirms its role in maintaining safe and positive patient healthcare outcomes and promoting a collegiate working environment and positive workplace culture.

\section{CONFLicts OF INTEREST Disclosure}

The authors declare that there is no conflict of interest.

\section{REFERENCES}

[1] Levinson W, Ginsburg S, Hafferty F, et al. Understanding medical professionalism. New York: McGraw-Hill; 2014.

[2] Cruess S, Cruess L. Professionalism and medicine's social contract. Focus on Health Professional Education: A Multi-Professional Journal. 2014; 16(1): 4-19. https://doi.org/10.11157/fohpe.v $16 i 1.52$

[3] Duphily N. Simulation education: A primer for professionalism. Teaching and Learning in Nursing. 2014; 9(3): 126-129. https: //doi.org/10.1016/j.teln.2014.03.003

[4] Wynia M, Latham S, Kao A, et al. Medical professionalism in society. The New England Journal of Medicine. 1999; 341(21): 1612-1616. https://doi.org/10.1056/NEJM199911183412112

[5] Wynia M. More than a list of values and desired behaviors: A foundational understanding of medical professionalism. Academic Medicine. 2014; 89(5): 712-714. https://doi.org/10.1097/ACM. 000000 0000000212

[6] Lombarts K, Plochg T, Thompson C, et al. Measuring professionalism in medicine and nursing: Results of a European survey. PLOSONE. 2014; 9(5): e97069. https://doi.org/10.1371/journal.po ne. 0097069

[7] Crookes P, Brown R, Della P, et al. The development of a preregistration nursing competencies assessment tool for use across Australian universities. Canberra: Australian Learning and Teaching Council; 2010. Available from: https://ro.uow.edu.au/hbsp apers /

[8] Nursing and Midwifery Board of Australia. Code of conduct for nurses [Internet]. 2018 [cited 2021 March 30]. Available from: https ://www.nursingmidwiferyboard.gov.au/Codes -Guidelines-Statements/Professional-standards.aspx

[9] The University of Notre Dame Australia. University leadership: Strategic plans [Internet]. 2019 [cited 2021 March 30]. Available from: https ://www.notredame.edu.au/__data/assets/pdf _file/0023/24764/Strategic-Plan-2018.pdf

[10] The University of Notre Dame Australia. Graduate Attributes [Internet]. 2019 [cited 2021 March 30]. Available from: https://www.notredame.edu.au/about/learning-and-t eaching-at-notre-dame/graduate-attributes

[11] Morin K, Bellack J. Student learning outcomes. Journal of Nursing Education. 2015; 54(3): Suppl S3-S4. https ://doi .org/10.392 8/01484834-20150217-10

Published by Sciedu Press
[12] Harvey N, Holmes C. Nominal group technique: An effective method for obtaining group consensus. International Journal of Nursing Practice. 2012; 18(2): 188-194. https ://doi.org/10.1111/j.1440 $-172 \mathrm{X} .2012 .02017 . \mathrm{x}$

[13] McMillan S, King M, Tully M. How to use the nominal group and Delphi techniques. International Journal of Clinical Pharmacy. 2016; 38(3): 655-662. https://doi.org/10.1007/s11096-016-025 $7-\mathrm{x}$

[14] Foth T, Efstathiou N, Vanderspank-Wright B, et al. The use of Delphi and nominal group technique in nursing education: A review. International Journal of Nursing Studies. 2016; 60: 112-120. https://doi.org/10.1016/j.ijnurstu.2016.04.015

[15] Keeney S, Hasson F, McKenna H. The Delphi technique in nursing and health research. West Sussex: Wiley-Blackwell; 2011.

[16] Newman I, Lim J, Pineda F. Content validity using a mixed methods approach: Its application and development through the use of a table of specifications methodology. Journal of Mixed Methods Research. 2013; 7(3): 243-260. https ://doi.org/10.1177/1558689813 476922

[17] Braun V, Clarke V. Successful qualitative research: A practical guide for beginners. Thousand Oaks; SAGE; 2013.

[18] Jarjoura D, Brennan RL. A Variance Components Model for Measurement Procedures Associated with a Table of Specifications. Applied Psychological Measurement. 1982; 6(2): 161-171. https: //doi.org/10.1177/014662168200600202

[19] Kolen MJ, Jarjoura D. Item Profile Analysis for Tests Developed According to a Table of Specifications. Applied Psychological Measurement. 1984; 8(3): 321-331. https://doi.org/10.1177/01 4662168400800309

[20] Notar CE, Zuelke DC, Wilson JD, et al. The table of specifications: insuring accountability in teacher made tests. Journal of Instructional Psychology. 2004; 31(2): 115.

[21] DiDonato-Barnes N, Fives H, Krause E S. Using a Table of Specifications to improve teacher-constructed traditional tests: an experimental design. Assessment in Education: Principles, Policy \& Practice. 2014; 21(1): 90-108. https://doi.org/10.1080/0969594X. 2 013.808173

[22] Bondy K. Criterion-referenced definitions for rating scales in clinical evaluation. The Journal of Nursing Education. 1993; 22(9): 376 https://doi .org/10 .3928/0148-4834-19831101-04 
[23] Fahrenwald N, Bassett S, Tschetter L, et al. Teaching core nursing values. Journal of Professional Nursing. 2005; 21(1): 46-51. https://doi.org/10.1016/j.profnurs.2004.11.001

[24] Miracle V. Professionalism. Dimensions of Critical Care Nursing. 2011; 30(2): 131-132. https://doi.org/10.1097/DCC.0b013e $31820525 f 4$

[25] Miller B, Adams D, Beck L. A behavioral inventory for professionalism in nursing. Journal of Professional Nursing: Official Journal of the American Association of Colleges of Nursing. 1993; 9(5): 290295. https ://doi .org/10.1016/8755-7223(93) 90055-H

[26] Tanaka M, Yonemitsu Y, Kawamoto R. Nursing professionalism: A national survey of professionalism among Japanese nurses. International Journal of Nursing Practice. 2014; 20(6): 579-587. https://doi.org/10.1111/ijn. 12201

[27] Levett-Jones T, Reid-Searl K, Bourgeois S. The clinical placement: An essential guide for nursing students. 4th ed. Chatswood; Elsevier: 2018. 